\title{
Editor's Note: Signal Processing for 5G-enabled Vehicular and UAV Communications
}

Published online: 22 October 2020

(C) Springer Science+Business Media, LLC, part of Springer Nature 2020

Journal of Signal Processing Systems gratefully acknowledges the editorial work of the scholars listed below on the special issue entitled "Signal Processing for 5G-enabled Vehicular and UAV Communications."

Prof. Kai-Ten Feng

Department of Electrical and Computer Engineering, National Chiao Tung University, Taiwan

Prof. Tomoaki Ohtsuki

Department of Information and Computer Science, Keio University, Japan

Publisher's Note Springer Nature remains neutral with regard to jurisdictional claims in published maps and institutional affiliations. 